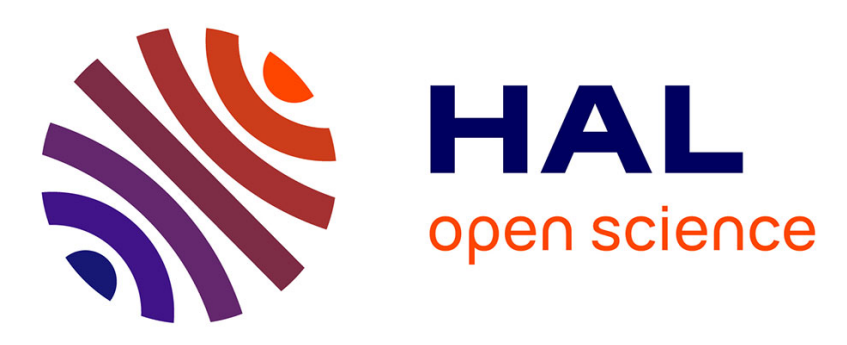

\title{
Apo(a) phenotyping and long-term prognosis for coronary artery disease.
}

\author{
M. A. Baños-González, M. A. Peña-Duque, Eduardo Anglés-Cano, M. A. \\ Martinez-Rios, A. Bahena, B. Valente-Acosta, G. Cardoso-Saldaña, J. \\ Angulo-Ortíz, A. de La Peña-Díaz
}

\section{To cite this version:}

M. A. Baños-González, M. A. Peña-Duque, Eduardo Anglés-Cano, M. A. Martinez-Rios, A. Bahena, et al.. Apo(a) phenotyping and long-term prognosis for coronary artery disease.: Apo(a) phenotype and coronary artery disease.. Clinical Biochemistry, 2010, 43 (7-8), pp.640-4. 10.1016/j.clinbiochem.2010.01.013 . inserm-00524992

\section{HAL Id: inserm-00524992 https://www.hal.inserm.fr/inserm-00524992}

Submitted on 10 Oct 2010

HAL is a multi-disciplinary open access archive for the deposit and dissemination of scientific research documents, whether they are published or not. The documents may come from teaching and research institutions in France or abroad, or from public or private research centers.
L'archive ouverte pluridisciplinaire HAL, est destinée au dépôt et à la diffusion de documents scientifiques de niveau recherche, publiés ou non, émanant des établissements d'enseignement et de recherche français ou étrangers, des laboratoires publics ou privés. 


\section{APO(a) PHENOTYPING AND LONG-TERM PROGNOSIS FOR CORONARY ARTERY DISEASE.}

Baños-González $M A^{1,3}$, Anglés-Cano $E^{6}$, Peña-Duque $M A^{1}$, Bahena $A^{5}$, Valente-Acosta $B^{2}$, Cardoso-Saldaña $G^{1}$, Escalante-Acosta $B^{3}$, Angulo-Ortíz $J^{1}$, De la Peña-Díaz $A^{1}, 2$.

1 Instituto Nacional de Cardiología "Ignacio Chávez", Departamentos de Biología Molecular, Cardiología Intervencionista, Endocrinología. México, D.F.

2 Facultad de Medicina, Departamento de Farmacología, Universidad Nacional Autónoma de México, México, D.F.

3 Centro de Investigación y Estudios Avanzados de IPN. Departamento de Biomedicina Molecular. México, DF.

4 Institut National de la Sante et de la Recherche Medicale, U919 Serine proteases in neurovascular pathology GIP Cyceron/Bd Henri Becquerel 14074cdx, Caen, France.

${ }^{5}$ Instituto Nacional de Neurología, México, D.F.

Corresponding author: Aurora de la Peña, Departamento de Farmacología, Edificio D, 1er piso, Facultad de Medicina, Universidad Nacional Autónoma de México. CP04510. México, D.F. Tel. $\begin{array}{llllllll}52 & 55 & 23 & 21 & 64 & \text { e } & \text { mail: }\end{array}$ aurorade2002@yahoo.com

Running head: Apo(a) phenotype and coronary artery disease.

Acknowledgements. Work supported by CONACYT 59896, DGAPA IN220308 and Instituto Científico Pfizer.

"Word-character count" of complete manuscript: 2650 
Background:The aim of this study is to identify whether the plasma concentration of $L p(a)$ helps predict the likelihood of cardiac death, non-fatal myocardial infarction, unstable angina, the need for additional revascularization procedures, and stroke.

Materials and Methods: We analyzed the clinical prognosis of 68 patients with coronary artery disease included in a case-controlled study which evaluated $L p(a)$ concentration, apo(a) size, and the ability of $\operatorname{Lp}(\mathrm{a})$ to bind to fibrin (de la Peña et al. Eur J of Clin Invest 2003; 33: 99-105). Cohort analysis of prognosis data was conducted over a median follow-up of 8 years in Mexico City at Instituto Nacional de Cardiología "Ignacio Chavez". We used Kaplan-Meier survival tables to evaluate cardiovascular and cerebrovascular events in the follow-up period.

Results: Based on a Kaplan-Meier analysis, apo-(a) isoforms of small size $(<22$ kringle domain repeats) are predictors of coronary risk. We also find an association between $\mathrm{Lp}(\mathrm{a})$ plasma concentration and apo(a) fibrin- binding with major adverse cardiovascular and cerebrovascular events, although without statistically significant results.

Conclusions: This study identifies small-sized apo(a) isoforms as an independent risk factor for cardiovascular and cerebrovascular events in patients with coronary artery disease in follow-up. We also found an association, although not significant, with $\mathrm{Lp}(\mathrm{a})$ plasma concentration and apo(a) fibrin-binding using multivariate statistic analysis.

Key words: apo(a) phenotyping, Lp(a) and long term prognosis 


\section{Introduction}

Lipoprotein (a) [Lp(a)] is a complex lipoprotein particle in human plasma. It is composed of apolipoprotein B (apoB100) and apolipoprotein (a) [apo(a)] which are linked by a disulfide bond. Apo(a) consists of a serine proteinase region and several kringle domains, derived from those of plasminogen but presenting some distinctive features. ${ }^{1}$ Only plasminogen's kringle 5 (one copy) and 4 (multiple copies) are present in apo(a). The copies of apo(a) kringle 4 are not alike: 10 different types have been recognized. ${ }^{2}$ Each type is present only once, except for kringle 4, type 2, which is present in multiple copies. This variation in copy number of kringle 4, type 2 domains results in structural heterogeneity of $\mathrm{Lp}(\mathrm{a})$ and isoforms whose molecular weights range from 280 to $800 \mathrm{kDa}$. Smaller isoforms of apo(a) with correspondingly fewer kringle 4, type 2 domains correlate inversely with $\mathrm{Lp}(\mathrm{a})$ plasma concentration. ${ }^{3}$

Plasma levels of $L p(a)$ vary greatly among individuals. Elevated plasma levels of $L p(a)$ have been shown to be an independent risk factor for coronary artery diseases (CAD). The level of $L p(a)$ is controlled by a single gene with multiple alleles; each allele affects the concentration of $L p(a)^{4}$.differently. The interindividual variation in plasma concentrations is almost entirely controlled by the apo(a) locus on chromosome $6 q 26-q 27$ and can be explained by a variable number of transcribed kringle4 repeats (KIV-VNTR).

External environmental factors have little impact on the pathogenicity of plasma Lp(a); however internal environmental characteristics such as the ability to undergo oxidation or the action of proteolytic or lipolytic enzymes can modify Lp(a)'s pathogenicity. Transient circumstances such as inflammation can also cause increases in plasma concentration and result in the apo-(a) being partially 
divided by polymorphonuclear neutrophils (PMNs) elastase, forming lower molecular weight structures ${ }^{5}$. It is important to stress this fact because when low molecular weight isoforms of apo(a) are present in the $L p(a)$ molecule, $L p(a)$ exhibits a greater affinity for fibrin and competitively inhibits plasminogen binding, thus generating a fibrinolytic shortfall ${ }^{6}$. Surprisingly, isolated apo(a) (10 to 34 kringles) has been shown to display a high affinity for fibrin ${ }^{7}$, independent of its size.

The pathological routes by which $L p(a)$ can lead to an atheroscleroticprone condition or by which a procoagulant mechanism is created by $L p(a)$ in the atherosclerotic plaque have been explored previously. Proposed mechanisms include the inhibition of the conversion of Glu-plasminogen to Lysplasminogen ${ }^{8}$, the alteration of the secretion of tissue-type plasminogen activator, the prolongation of fibrinolysis time due to the thinning of fibrin fibers ${ }^{9}$, an increase in binding to tissue factor pathway inhibitor (TFPI) ${ }^{10}$, and an increase in platelet aggregation through the interaction of apo(a) with a specific receptor at the platelet surface ${ }^{11}$ which induces endothelial dysfunction ${ }^{12-13}$. In transgenic mice, $\operatorname{Lp}(a)$ has been shown to increase the concentration of cholesterol-rich remnant lipoproteins and the atherosclerosis lesion area in the aortic root ${ }^{14}$. Moreover, $L p(a)$ shows a synergistic effect with homocysteine ${ }^{15}$ another atherogenic particle.

It is also important to note that apo(a) has properties independent of Lp(a). For example, oxidized proinflammatory phospholipids in apoB-100 particles are preferentially sequestered on $\operatorname{Lp}(a),{ }^{16}$ which induces avid uptake by monocyte-macrophages recruits ${ }^{17}$. Another very interesting study shows evidence that the origin of oxidized phospholipids in $L p(a)$ is apo(a) rather than 
$\mathrm{LDL}$, independent of plasma concentration or the isoform of apo(a) ${ }^{18}$. It has been shown that vascular endothelial cell growth, migration, contraction and cell permeability ${ }^{19},{ }^{20}$ are all induced by apo(a).

The evidence suggests that there is no single pathophysiological mechanism leading to the development of CAD and induced by $L p(a)$. Several mechanisms may be involved, and different populations may display different sensitivities. The association between $L p(a)$ and cardiovascular disease has been the subject of numerous studies, in vitro and in vivo. Population retrospective studies consistently support a pathophysiologic role for $L p(a)$, but prospective studies have been inconsistent. Two meta-analyses of prospective studies ${ }^{21},{ }^{22}$ with at least 1 year of follow-up showed a risk ratio of $1.40(95 \% \mathrm{Cl}$ $1.22-1.57)$ and $1.6(95 \% \mathrm{Cl} 1.4$ to 1.8$)$, respectively. These features demonstrate a clear association between $L p(a)$ and CAD in a Caucasian population, although this conclusion is not necessarily generalizable to a different population with distinct genetic profiles. Mexicans living in the United States have decreased $L p(a)$ plasma concentrations relative to non-Hispanic whites $^{23}$. Native Mexicans and the Mestizo group living in Mexico ${ }^{24}$ have significant differences in $L p(a)$ concentration and apo(a) phenotype distribution between them, and there is evidence that atherothrombotic disease is associated with apo(a) fibrin-binding and small size apo(a) in this population ${ }^{25}$. In the present work we analyze the impact of apo(a) on the course of cardiovascular and cerebrovascular diseases in a population using a functional approach (the binding of apo(a) and fibrin), $L p(a)$ plasma concentration, and apo(a) phenotyping determined about eight years previously. Death, non-fatal myocardial infarction, unstable angina, need for myocardial revascularization 
(percutaneous or surgical), and ischemic stroke were monitored over 8 years of follow-up.

\section{Methods}

We included patients born in Mexico who had a history of CAD defined as myocardial infarction and/or unstable angina (> 3 months) or stable angina and who had been followed up at the outpatient clinic of the National Institute of Cardiology "Ignacio Chavez". From January 1997 to December 1999, we conducted a case controlled study with the aim of evaluating the impact of Lp(a) in $C A D$ and cerebrovascular disease. Sixty-eight patients with $C A D$ were monitored and included in this analysis.

Patients were considered positive for type 2 diabetes mellitus if they were receiving hypoglycemic and/or insulin treatment or if fasting glucose levels were $126 \mathrm{mg} / \mathrm{dL}$ on 2 or more occasions. Patients were classified as having systemic hypertension with a prior diagnosis or with established antihypertensive treatment. Dyslipidemic patients had hypercholesterolemia (as determined by prior diagnosis, total cholesterol levels equal to or greater than $240 \mathrm{mg} / \mathrm{dL}$, LDL cholesterol levels equal to or greater than $160 \mathrm{mg} / \mathrm{dL}$ or HDL cholesterol levels lower than $40 \mathrm{mg} / \mathrm{dL}$ ) and/or hypertriglyceridemia (as determined by prior diagnosis, treatment with fibrates or serum triglycerides equal to or greater than $150 \mathrm{mg} / \mathrm{dL}$ ). Patients were classified as prior smokers if they had a history of smoking 5 or more cigarettes a day and had abstained for longer than a year. Patients were considered active smokers if they smoked 5 or more cigarettes a day at the beginning of the study or had abstained for less than a year. All patients were treated with aspirin, statins, beta blockers and angiotensinconverting enzyme inhibitors (ACE-i). 
The extent of CAD was estimated by determining the percentage of internal luminal narrowing. Involvement of one vessel was considered hemodynamically significant with more than a $50 \%$ reduction in the diameter of an important vessel (left anterior descending, circumflex or right coronary). Involvement of 2 vessels meant significant stenosis in two coronary vessels or a narrowing of $50 \%$ or more in the left main trunk, and involvement of 3 vessels meant significant stenosis in three coronary vessels.

As previously reported ${ }^{33} \mathrm{Lp}(\mathrm{a})$ plasma concentration was measured employing an immunonephelometric method (reagents and equipment from Beckman Co, Palo Alto CA, USA).

Apo(a) isoforms were detected by SDS-PAGE of plasma under reducing conditions. Apo(a) isoforms were identified using a standard composed of recombinant apo(a) containing 10, 14, 18, 26 and 34 kringles $^{26}$.

The binding assay is based on the ability of $L p(a)$ to compete with plasminogen for fibrin binding ${ }^{27},{ }^{28}$. The amount of $L p(a)$ bound is expressed in nanomoles of apo(a) by referring to a calibration curve. The standard curve was obtained from a reference standard composed of equimolar amounts of five recombinant apo(a) isoforms of different lengths (10 to 34 kringles).

Data were collected from medical records or by telephone interviews. Major adverse cardiovascular and cerebrovascular events (MACCE) were recorded during follow-up. A comprehensive catalog of all causes of death, myocardial infarction, unstable angina and/or percutaneous revascularization or bypass surgery, and ischemic stroke was compiled Myocardial infarction was defined as angina symptoms with ST-segment elevation and/or elevated necrosis cardiac markers at least 3 times above the normal value. Unstable 
angina was defined as characteristic symptoms of angina in cresendo or angina at rest. Deaths were classified as either cardiac or not cardiac. Deaths that could not be classified were considered cardiac.

\section{Statistics}

We used descriptive statistics with median \pm SD and median with minimum and maximum values in accordance with their distribution. The Kolmogorov-Smirnov test was used as evidence of normality. The student test or the Mann-Whitney $U$ test was used to compare continuous variables between groups. Categorical variables were reported as absolute values or percentages and compared with a chi-square test or Fisher exact test for frequencies lower than 5. $\mathrm{Lp}(\mathrm{a})$ concentration, binding and apo(a) size, as well as age, gender, traditional risk factors, three-vessel disease, and left ventricle systolic dysfunction were included in a logistic regression model. Apo(a) size was dichotomized for analysis at the $22 \mathrm{~K}$ isoform. Low molecular weight apo(a) isoforms were designated by convention as $\leq 22 \mathrm{~K}-\mathrm{IV}$ repeats ${ }^{29}$.

The primary end point of the study was the incidence of MACCE at follow-up. The primary end point was defined to be the event which occurred first. Events were counted only once,. We used tables of Kaplan-Meier survival to evaluate the primary endpoint as either death, non-fatal myocardial infarction, need for revascularization (percutaneous or surgical) or ischemic stroke. We censored cases that were losses in monitoring (patients lost to follow-up were considered at risk until the date of last contact, at which point they were removed from consideration). Comparison between groups was carried out using the logrank test (Log Rank). All tests were 2-tails. Differences were 
considered significant if $p<0.05$. All analyses were performed with SPSS (version 13.0).

\section{Results}

Clinical and demographic characteristics of patients are presented in Table 1. Prevalent risk factors in both groups were hypertension, dyslipidemia and smoking. At baseline, no differences were observed for age, sex, cardiovascular risk factors, profile of lipids, and medical treatment between both groups. The majority of patients were undergoing pharmacological treatment including aspirin, betablockers and ACEi. A few patients were taking statins and calcium channels blockers at baseline. There was a statistically significant difference in $L p(a)$ concentration in patients with small apo(a) isoforms compared with large apo(a) isoforms $(p=0.02)$. Interestingly, there were no differences in apo(a) fibrin binding in the groups.

In the multivariate analysis (Table 2), apo(a) $\mathrm{KIV} \leq 22$ was an independent risk factor for cardiovascular and cerebrovascular events in patients with CAD (odds ratio (OR) of $4.4, \mathrm{Cl}$ of $1.24-15.62, \mathrm{p}=0.021$ ). Apo(a) binding and $\mathrm{Lp}(\mathrm{a})>30 \mathrm{mg} / \mathrm{dL}$ did show a tendency for an increased risk of MACCE, although without the statistical significance seen for apo(a) K-IV $\leq 22$. MACCE in the follow up.

Clinical follow-up was achieved in patients after an average of 6.9 years \pm 3.04 . There were 3 deaths in the small kringles group (10\%) and no deaths in the large kringles group $(p=0.081)$. MACCE-free survival at follow-up was $27 \%$ in patients with apo(a) KIV $\leq 22$ and $48 \%$ in patients with the larger apo(a) $\mathrm{KIV}>22$ isoform $(P=0.051)$. Incidence of MACCE at follow-up was significantly 
lower in patients who had the large isoform compared to patients with the small isoform (Table 3).

\section{Discussion}

The evidence presented here shows that the best approach to evaluate the cardiovascular risk associated with $L p(a)$ is to determine the isoforms of circulating apo(a). ${ }^{30}$ When just measuring plasma concentration of $L p(a)$, it is not always possible to find such an association ${ }^{31}$. Nevertheless, Kamstrup et al, in a recent meta-analysis of 36 prospective studies, found a modest association of elevated $L p(a)$ concentration with coronary heart disease and stroke ${ }^{32}$.

We previosly reported ${ }^{33}$ experimental evidence to support the hypothesis that smaller-sized isoforms of apo(a) increased the potential antifibrinolytic effect in ischemic cardiopathy and cerebrovascular disease. This effect was more evident in the cerebrovascular group, suggesting the existence of peculiar and poorly understood differences in antithrombotic mechanisms in the cerebral and coronary arteries of these patients.

In this study, we found an increase in MACCE even when follow-up was only two years after initial contact in the apo(a) KIV $\leq 22$ group, demonstrating that, in a hospital-based population, small apo(a) isoforms are associated with the development of major adverse cardiovascular and cerebrovascular events. These data agree with other studies that found an association between $\mathrm{Lp}(\mathrm{a})$ levels and stroke and death from vascular disease in the elderly. ${ }^{34}$

When we examined the relationship between apo(a) fibrin binding and MACCE, we did find an association, although it was not significant according to the multivariate statistical analysis. It is possible that mechanisms other than apo(a) fibrin binding could influence the thrombogenicity of apo(a) and the risk 
of adverse cardiovascular events. Apo(a) has the ability to preferentially bind proinflammatory oxidized phospholipidl (OxPL) $)^{35}$, and it has been shown that there is an association between OxPL and small apo(a) isoforms despite differences in $L p(a)$ levels.

The interaction of $L p(a)$ with other particles likely enhances its atherogenic and thrombogenic properties. The combination of high $L p(a)$ plasma concentrations and LDL cholesterol levels increased the risk and advance of $C A D^{36}$. Also homocysteine can increase the antifibrinolytic effect of $L p(a)$ by dissociating apo(a) from the $L p(a)$ particle ${ }^{3738}$

This study does have limitations, including the fact that the analysis was retrospective and the fact that we did not include in the analysis the response of patients to different treatments. However, we believe that when the results presented here are carefully considered, we can conclude that there is a mild mortality risk associated with apo(a) K-IV $\leq 22$ in Mexican patients with coronary artery disease. This association may prove clinically useful in risk stratification, helping identify patients with an increased risk of major adverse cardiovascular and cerebrovascular events in the long term. 


\section{BIBLIOGRAPHY}

1 McLean JW, Tomlinson JE, Kuang WJ, Eaton DL, Chen EY, Fless GM, et al. cDNA sequence of human apolipoprotein(a) is homologous to plasminogen. Nature 1987;300:132-7.

2 Guevara J Jr, Knapp RD, Honda S, Northup SR, Morrisett JD. A structural assessment of the apo (a) protein of human lipoprotein (a). Proteins 1992;12:188-99.

3 Utermann G, Menzel HJ, Kraft HG, Duba HC, Kemmler HG, Seitz C. Lp (a) glycoprotein phenotypes: Inheritance and relation to Lp (a)-lipoprotein concentrations in plasma. J Clin Invest 1987;80:458-65.

4 De la Peña-Díaz A, Izaguirre-Avila R, Anglés-Cano E. Lipoprotein Lp(a) and atherothrombotic disease. Arch Med Res 2000; 31: 353-359.

5 Lamanuzzi LB, Mtairag el M, Pepe G, Anglés-Cano E. Neutrophils stimulated by apolipoprotein(a) generate fragments that are stronger inhibitors of plasmin formation than apo(a). Thromb Haemost. 2004;92:1066-75.

6 Anglés-Cano E, de la Peña Díaz A, Loyau S.Inhibition of fibrinolysis by lipoprotein(a). Ann N Y Acad Sci. 2001;936:261-75.

7 Kang C, Dominguez M, Loyau S, Miyata T, Durlach V, Anglés-Cano E. Lp(a) particles mold fibrin-binding properties of apo(a) in size-dependent manner: a study with different-length recombinant apo(a), native $\mathrm{Lp}(\mathrm{a})$, and monoclonal antibody. Arterioscler Thromb Vasc Biol. 2002;22:1232-8.

8 Feric NT, Boffa MB, Johnston SM, Koschinsky ML. Apolipoprotein(a) inhibits the conversion of Glu-plasminogen to Lys-plasminogen: a novel mechanism 
for lipoprotein(a)-mediated inhibition of plasminogen activation. J Thromb Haemost. 2008;6::2113-20.

9 Undas A, Stepien E, Tracz W, Szczeklik A. Lipoprotein(a) as a modifier of fibrin clot permeability and susceptibility to lysis. J Thromb Haemost. 2006;4:973-5.

10 Caplice NM, Panetta C, Peterson TE, Kleppe LS, Mueske CS, Kostner GM, et al. Lipoprotein (a) binds and inactivates tissue factor pathway inhibitos: a novel link between lipoproteins and thrombosis. Blood 2001;98 2980-87.

11 Martínez C, Rivera J, Loyau S, Corral J, González-Conejero R, Lozano ML, Vicente V, Anglés-Cano E.Binding of recombinant apolipoprotein(a) to human platelets and effect on platelet aggregation. Thromb Haemost. 2001 Apr;85(4):686-93

12 Cho T, Jung Y, Koschinsky ML. Apolipoprotein(a), through its strong lysinebinding site in $\mathrm{KIV}\left(10^{\prime}\right)$, mediates increased endothelial cell contraction and permeability via a Rho/Rho kinase/MYPT1-dependent pathway.J Biol Chem. 2008;283:30503-12.

13 Pellegrino M, Furmaniak-Kazmierczak E, LeBlanc JC, Cho T, Cao K, Marcovina SM, Boffa MB, Côté GP, Koschinsky ML.The apolipoprotein(a) component of lipoprotein(a) stimulates actin stress fiber formation and loss of cell-cell contact in cultured endothelial cells. J Biol Chem. 2004;279:6526-33.

14 Devlin CM, Lee SJ, Kuriakose G, Spencer C, Becker L, Grosskopf I, Ko C, Huang LS, Koschinsky ML, Cooper AD, Tabas I. An apolipoprotein(a) peptide delays chylomicron remnant clearance and increases plasma remnant lipoproteins and atherosclerosis in vivo.Arterioscler Thromb Vasc Biol. 2005;25:1704-10. 
15 Nardulli M, Durlach V, Pepe G, Anglés-Cano E. Mechanism for the homocysteine-enhanced antifibrinolytic potential of lipoprotein(a) in human plasma. Thromb Haemost. 2005;94:75-81.

16 Kiechl S, Willeit J, Mayr M, Viehweider B, Oberhollenzer M, Kronenberg F, Wiedermann CJ, Oberthaler S, Xu Q, Witztum JL, Tsimikas S. Oxidized phospholipids, lipoprotein(a), lipoprotein-associated phospholipase A2 activity, and 10-year cardiovascular outcomes: prospective results from the Bruneck study. Arterioscler Thromb Vasc Biol. 2007;27:1788-95.

17 Sotiriou SN, Orlova VV, Al-Fakhri N, Ihanus E, Economopoulou M, Isermann B, Bdeir K, Nawroth PP, Preissner KT, Gahmberg CG, Koschinsky ML, Chavakis T. Lipoprotein(a) in atherosclerotic plaques recruits inflammatory cells through interaction with Mac-1 integrin.FASEB J. 2006;20:559-61.

18 Edelstein C, Philips B, Pfaffinger D, Scanu AM. The oxidized phospholipids linked to human apolipoprotein(a) do not derive from circulating low-density lipoproteins and are probably of cellular origin.FASEB J. 2009;23:950-6.

19 Liu L, Craig AW, Meldrum HD, Marcovina SM, Elliott BE, Koschinsky ML Apolipoprotein(a) stimulates vascular endothelial cell growth and migration and signals through integrin alphaVbeta3..Biochem J. 2009;418:325-36

20 Cho T, Jung Y, Koschinsky ML Apolipoprotein(a), through its strong lysinebinding site in $\mathrm{KIV}\left(10^{\prime}\right)$, mediates increased endothelial cell contraction and permeability via a Rho/Rho kinase/MYPT1-dependent pathway. J Biol Chem. 2008;283:30503-12.

21 Craig WY, Neveux LM, Palomaki GE, Cleveland MM, Haddow JE.Lipoprotein(a) as a risk factor for ischemic heart disease: metaanalysis of prospective studies. Clin Chem. 1998 Nov;44(11):2301-6. 
22 Danesh J, Collins R, Peto R.Lipoprotein(a) and coronary heart disease.

Meta-analysis of prospective studies. Circulation. 2000 Sep 5;102(10):10825.

23Haffner SM, Gruber K K, Morales PA, Hazuda HP, Valdez RA, Mitchell BD, Stern MP.Lipoprotein(a) concentrations in Mexican Americans and nonHispanic whites: the San Antonio Heart Study. Am J Epidemiol 1992;136:1060-8.

24Cardoso-Saldaña G, De La Peña-Díaz A, Zamora-González J, GomezOrtega R, Posadas-Romero C, Izaguirre-Avila R, Malvido-Miranda E, Morales-Anduaga ME, Anglés-Cano E. Ethnicity and lipoprotein(a) polymorphism in Native Mexican populations. Ann Hum Biol. 2006;33:20212.

25 De la Peña-Díaz A, Cardoso Saldaña G, Zamora-González J, Barinagarrementeria F, Loyau S, Izaguirre R, Anglés-Cano E. Functional approach to investigate $L p(a)$ in ischaemic heart and cerebral diseases. Eur $\mathrm{J}$ of Clin Invest 2003; 33: 99-105.

26 Anglés-Cano E, Loyau S, Cardoso-Saldaña G, Couderc R, Gillery P. A novel kringle-4 number-based recombinant apo[a] standard for human apo[a] phenotyping. J Lipid Res. 1999;40:354-9

27 Soulat T, Loyau S, Baudouin V, Maisonneuve L, Hurtaud-Roux MF, Schlegel $\mathrm{N}$, Loirat C, Anglés-Cano E. Effect of individual plasma lipoprotein(a) variations in vivo on its competition with plasminogen for fibrin and cell binding: An in vitro study using plasma from children with idiopathic nephrotic syndrome. Arterioscler Thromb Vasc Biol 2000;20:575-84. 
28 Hervio L, Durlach V, Girard-Globa A, Anglés-Cano E. Multiple binding with identical linkage: a mechanism that explains the effect of lipoprotein(a) on fibrinolysis. Biochemistry 1995;34:13353-8

29 Longenecker JC, Klag MJ, Marcovina SM, Liu YM, Jaar BG, Powe NR, Fink NE, Levey AS, Coresh J. High lipoprotein(a) levels and small apolipoprotein(a) size prospectively predict cardiovascular events in dialysis patients. J Am Soc Nephrol. 2005;16:1794-802.

30 Kronenberg F, Kronenberg MF, Kiechl S, Trenkwalder E, Santer P, Oberhollenzer F, et al. Role of lipoprotein (a) and apolipoprotein (a) phenotype in atherogenesis: prospective results from the Bruneck study. Circulation 1999; 100:1154-60

31 Marcucci R, Brogi D, Sofi F, Giglioli C, Valente S, A Alessandrello Liotta, M Lenti,A M Gori, D Prisco, R Abbate, G F Gensini. PAI-1 and homocysteine, but not lipoprotein (a) and thrombophilic polymorphisms, are independently associated with the occurrence of major adverse cardiac events after successful coronary stenting. Heart 2006;92: 377-381.

32 Kamstrup PR, Tybjaerg-Hansen A, Steffensen R, Nordestgaard BG Genetically elevated lipoprotein(a) and increased risk of myocardial infarction. JAMA. 2009;301:2331-9

33 De la Peña-Díaz A, Cardoso Saldaña G, Zamora-González J, Barinagarrementeria F, Loyau S, Izaguirre R, Anglés-Cano E. Functional approach to investigate $L p(a)$ in ischaemic heart and cerebral diseases. Eur $\mathrm{J}$ of Clin Invest 2003; 33: 99-105. 
34 Ariyo A, Thach C, Tracy R,for the Cardiovascular Health Study Investigators. Lp(a) Lipoprotein, Vascular Disease, and Mortality in the Elderly. N Engl J Med 2003;349:2108-15.

35 Tsimikas S, Clopton P, Brilakis ES, Marcovina SM, Khera A, Miller ER, de Lemos JA, Witztum JL.Relationship of oxidized phospholipids on apolipoprotein B-100 particles to race/ethnicity, apolipoprotein(a) isoform size, and cardiovascular risk factors: results from the Dallas Heart Study. Circulation. 2009;119:1711-9.

36 Armstrong VW, Cremer P, Eberle E, Manke A, Schulze F, Wieland H, Kreuzer $\mathrm{H}$, Seidel $\mathrm{D}$. The association between serum $\mathrm{Lp}(\mathrm{a})$ concentrations and angiographically assessed coronary atherosclerosis: dependence on serum LDL levels. Atherosclerosis. 1986;62:249 -257.

37 Nardulli M, Durlach V, Pepe G, Anglés-Cano E. Mechanism for the homocysteine-enhanced antifibrinolytic potential of lipoprotein(a) in human plasma. Thromb Haemost. 2005 Jul;94(1):75-81.

38 Kronenberg F, Kronenberg MF, Kiechl S, Trenkwalder E, Santer P, Oberhollenzer F, et al. Role of lipoprotein (a) and apolipoprotein (a) phenotype in atherogenesis: prospective results from the Bruneck study. Circulation 1999; 100:1154-60 
Table 1. Demographic and clinical characteristics of patients according to apo(a) size, $(n=68)$.

\begin{tabular}{|c|c|c|c|}
\hline Variables & $\begin{array}{c}\text { Apo(a) } K-I V \leq 22 \\
n=30\end{array}$ & $\begin{array}{c}\text { Apo(a) K-IV >22 } \\
n=38\end{array}$ & $\mathbf{p}$ \\
\hline Age, median \pm SD & $51.8 \pm 10.3$ & $53.2 \pm 10.7$ & 0.557 \\
\hline Male, $\mathbf{n}(\%)$ & $24(80)$ & $34(89)$ & 0.318 \\
\hline Systemic hypertension, $\mathrm{n}(\%)$ & $15(50)$ & $18(47)$ & 0.829 \\
\hline Diabetes mellitus, n(\%) & $7(23)$ & $3(7)$ & 0.094 \\
\hline Previous smoking habits, $\mathrm{n}(\%)$ & $9(30)$ & $15(39)$ & 0.417 \\
\hline Present smoking habits, $n(\%)$ & $16(53)$ & $17(44)$ & 0.481 \\
\hline Dyslipidemia, n(\%) & $14(46)$ & $21(55)$ & 0.481 \\
\hline Previous MI, $n(\%)$ & $29(96)$ & $32(84)$ & 0.124 \\
\hline Body-mass index, median \pm SD & $26.7 \pm 4.1$ & $25.9 \pm 2.9$ & 0.341 \\
\hline Cholesterol (mg/dl) median \pm SD & $192 \pm 42.8$ & $196 \pm 39.1$ & 0.687 \\
\hline Triglycerides (mg/dl) median +SD & $215+95.6$ & $195+102.4$ & 0.417 \\
\hline LVEF (\%) & $51.2+8.2$ & $53.2+10.7$ & 0.389 \\
\hline LVEF low (<50\%), n (\%) & $11(36)$ & $10(26)$ & 0.359 \\
\hline Multivessel disease, n (\%) & $5(16)$ & $5(13)$ & 0.740 \\
\hline $\begin{array}{l}\text { Apo(a) fibrin binding, (median, } \\
\text { minimum-maximum value) }\end{array}$ & $0.14(0.01-0.58)$ & $0.13(0-0.60)$ & 0.546 \\
\hline $\begin{array}{l}\text { Apo(a) high-affinity binding to fibrin, } n \\
\text { (\%) }\end{array}$ & $7(23.3)$ & $5(13.2)$ & 0.274 \\
\hline
\end{tabular}




\begin{tabular}{|l|l|l|l|}
\hline $\begin{array}{l}\text { Lp (a) lipoprotein (mg/dL), median } \\
\text { (minimum-maximum value) }\end{array}$ & $26(0-128)$ & $10(0-128)$ & 0.021 \\
\hline Medical treatment, $\mathbf{n}(\%)$ & $26(86)$ & $36(94)$ & 0.394 \\
$-\quad$ Aspirin & $7(23)$ & $14(36)$ & 0.231 \\
$-\quad$ Estatin & $16(53)$ & $19(50)$ & 0.785 \\
$-\quad$ Beta-blocker & $11(36)$ & $14(36)$ & 0.988 \\
$-\quad$ Calcium channel blockers & $11(36)$ & $19(50)$ & 0.272 \\
\hline
\end{tabular}

$L V E F=$ left ventricular ejection fraction, apo(a)K-IV $\leq 22=$ low molecular weight apolipoprotein-(a) isoforms, $L p(a)=$ lipoprotein-(a), ACE- $\mathrm{i}=$ angiotensin converting-enzyme inhibitors, $\mathrm{SD}=$ standard deviation, $\mathrm{Ml}=$ myocardial infarction. 
Table 2. Variables included in a logistic regression model

\begin{tabular}{|l|r|r|r|r|}
\hline & \multicolumn{1}{|c|}{ Sig. } & \multicolumn{1}{c|}{ OR } & \multicolumn{2}{|c|}{$95.0 \% \mathrm{Cl}$} \\
\hline & & & \multicolumn{1}{c|}{ Lower } & \multicolumn{1}{c|}{ Upper } \\
\hline Male Gender & .611 & .667 & .14 & 3.17 \\
Hypertension & .524 & .704 & .239 & 2.07 \\
& & & & \\
Diabetes Mellitus & .299 & 2.359 & .467 & 11.916 \\
& & & & \\
Smoking & .536 & 1.443 & .452 & 4.612 \\
Dyslipidemia & .379 & 0.618 & .211 & 1.805 \\
& & & & \\
Low LVEF & .931 & 1.052 & .329 & 3.369 \\
Multivessel disease & .366 & 0.472 & 0.093 & 2.398 \\
Apo(a) KIV <22K & .021 & 4.418 & 1.249 & 15.625 \\
Apoa) binding & .276 & 2.354 & .505 & 10.968 \\
Lp (a) $>30$ mg/dL & .563 & 1.547 & .353 & 6.787 \\
& & & & \\
\hline
\end{tabular}

$L p(a)=$ lipoprotein $(a) ; a p o(a)=$ apolipoprotein $(a) ; M I=$ myocardial infarction;

$\mathrm{LVEF}=$ left ventricular ejection fraction; $\mathrm{OR}=$ odds ratio; $\mathrm{Cl}=$ confidence

intervals 
Table 3. Incidence of major adverse cardiovascular and cerebrovascular events.

\begin{tabular}{|l|l|l|l|}
\hline & Apo(a) KIV<22, n=30 & Apo(a) KIV >22, n=38 & OR(95\% Cl) \\
\hline Death & $3(10 \%)$ & 0 & $2.4(1.8-3.2)$ \\
$\quad$ Cardiac $\quad$ Not cardiac & $1(3.3 \%)$ & & \\
\hline Myocardial infarction & $4(13.3)$ & $5(13.2)$ & \\
\hline $\begin{array}{l}\text { Unstable angina } \\
\text { Ischemic stroke }\end{array}$ & $5(16.7)$ & $6(15.8)$ & $1.0(0.4-2.2)$ \\
\hline $\begin{array}{l}\text { Coronary } \\
\text { revascularization }\end{array}$ & $3(10)$ & $1(2.6)$ & $1.0(0.5-2.1)$ \\
\hline MACCE & $19(63 \%)$ & $2(5.3)$ & $1.9(1.1-3.2)$ \\
\hline
\end{tabular}

$\mathrm{OR}=$ odds ratio; $\mathrm{Cl}=$ confidence intervals 
Figure 1.

\section{Kaplan-Meier Analysis}

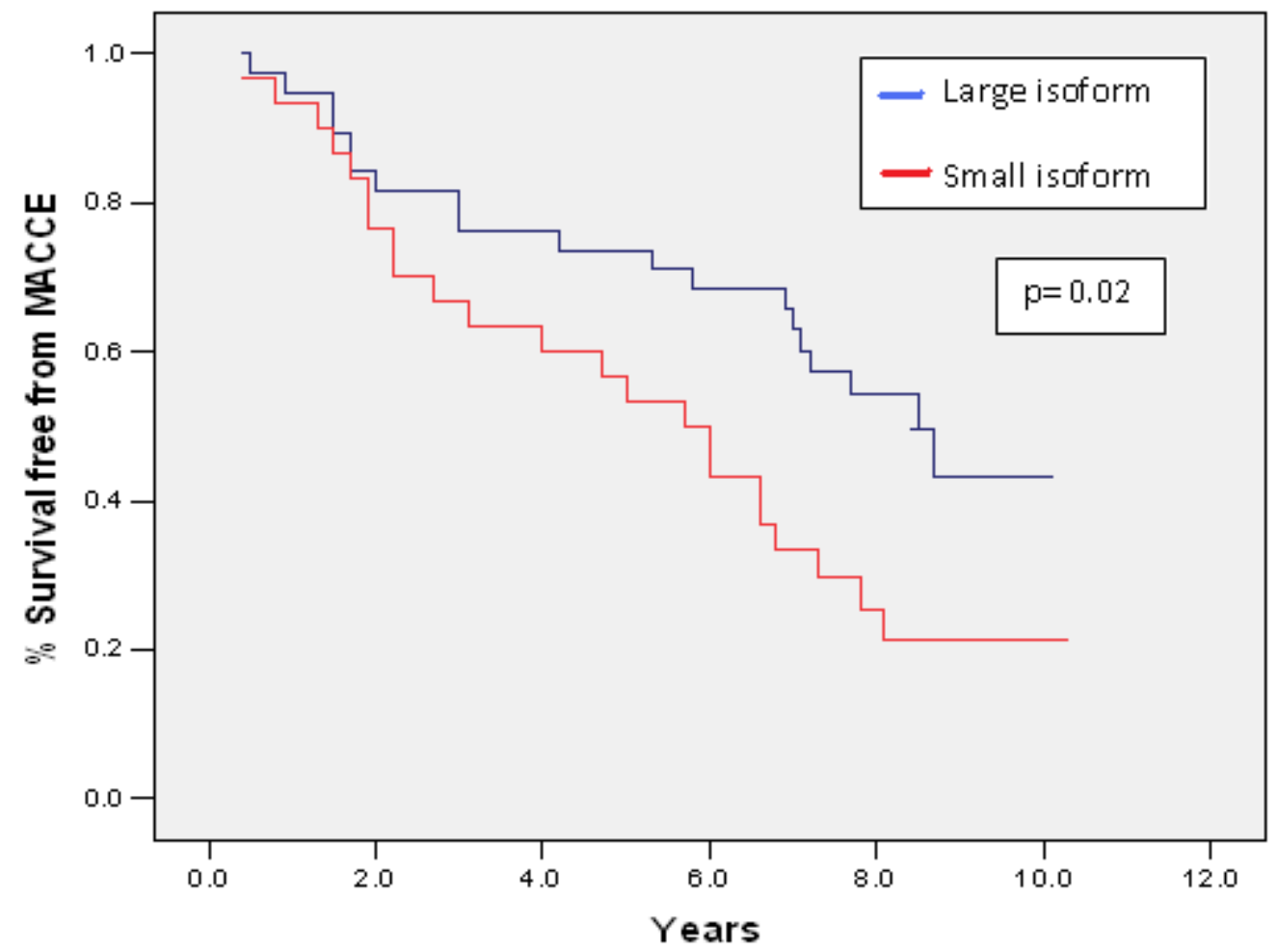

Patients at risk

\begin{tabular}{|l|l|l|l|l|l|l|l|l|l|l|}
\hline $\begin{array}{l}\text { Apo(a) } \\
\text { KIV<22 }\end{array}$ & $\mathbf{3 0}$ & $\mathbf{2 8}$ & $\mathbf{2 3}$ & $\mathbf{2 0}$ & $\mathbf{1 9}$ & $\mathbf{1 7}$ & $\mathbf{1 5}$ & $\mathbf{1 0}$ & $\mathbf{6}$ & $\mathbf{5}$ \\
\hline $\begin{array}{l}\text { Apo(a) } \\
\text { KIV>22 }\end{array}$ & 38 & 36 & 32 & 31 & 29 & 28 & 26 & 24 & 18 & 6 \\
\hline Total & 68 & 64 & 55 & 51 & 48 & 45 & 41 & 34 & 24 & 11 \\
\hline
\end{tabular}

Freedom from major adverse cardiovascular and cerebrovascular events (death, myocardial infarction, unstable angina, myocardial revascularization , and stroke) at 10 years. 